\title{
Community engagement through sport: University partnerships to promote youth
} development

By: Michael A. Hemphill and Tom Martinek

Hemphill, M. A. \& Martinek, T. (2017). Community engagement through sport: University partnerships to promote youth development. Kinesiology Review, 6(4), 311-316.

Accepted author manuscript version reprinted, by permission, from Kinesiology Review, 2017, 6 (4): 311-316, https://doi.org/10.1123/kr.2017-0027. (C) Human Kinetics, Inc.

\begin{abstract}
:
Many kinesiology departments engage in partnerships that aim to promote positive youth development through physical activity. These partnerships are often enhanced by mutually beneficial goals and shared decision making between university and community partners. This paper describes how sport has been at the center of two university-community partnerships that have helped to teach life skills to youth. We draw upon our experience working with community partners to illuminate challenges and opportunities for youth-focused partnerships. The programs include an emphasis on sustainability. As kinesiology programs continue to enhance their efforts to partner and support youth development, case studies such as this may help inform our efforts.
\end{abstract}

Keyword: life skills | community-engaged scholarship | sport-based youth development

\section{Article:}

Physical activity and sport programs provide a context for positive youth development where youth learn physical skills and develop personal and social responsibility (Holt, 2016). Some research suggests that such skills learned in a sport setting are transferrable to other domains (Lee \& Martinek, 2013). Consequently, several kinesiology programs include community engagement initiatives that aim to serve youth in their communities, generate new scholarship, and develop new resources and opportunities on their campus. The sustainability of community engagement programs relies on partnerships between several key stakeholders (Hemphill et al., 2012). For example, successful programs rely on contributions from university faculty, staff, and students, nonprofit organizations, philanthropists, and families, among others. This article describes two models of community engagement partnerships that aim to support at-risk youth (i.e., Hemphill \& Richards, 2016; Martinek, 2016). Included are practical examples of how the programs work and ways in which the individual partner's needs are met. We position these descriptions with several considerations that surround the planning and successful 
implementation of collaborative programming. One of these is acknowledging the contributions that each partner makes to the health and vitality of the program initiatives. A portrayal of the type of partners who engage in collaborative programming must also be considered along with the resources and other supporting features that each can offer. Future directions for the sustainability and enhancement of community engagement partnerships in the kinesiology programs are also offered.

\section{The Importance of Partnerships}

Quite simply, partnerships have been critical to the success of our programs. In working with our community partners, we are always reminded of the many benefits derived from our partnerships. Certainly, the history of collaborative initiatives between universities and community agencies have been both fruitful and full of celebratory outcomes. We also have learned from those challenges that have occurred as they have made us rethink future approaches to program planning. In either case, we feel that the benefits have been received by both parties and have created a network of social interaction that have fostered a spirit of cooperation and mutual support. And, in some cases, we have followed a golden rule offered by the Harvard political scientist, Robert Putnam: "We do this for you without expecting anything specific back from you" (Putnam, 2001, p. 21). The importance of partnerships cannot be understated and the full thrust of them is seen in a number of ways.

University partnerships with local communities provide mutual benefits to all stakeholders. For example, communities have opportunities to leverage the unique resources of the university to help meet their needs. One of the most basic ways that partnerships have become important to universities is they have helped to diffuse the perception that universities operate as a separate entity from the communities in which they reside. That is, there has been widespread criticism of higher education's disconnection from communities. Fortunately, universities such as ours have established a foothold in its commitment to be a community-engaged institution (Driscoll, 2008). This has not only positioned the university to respond to various community needs but has also developed its students' civic capacity (Strand, Marullo, Cutforth, Stoecker, \& Donahue, 2003).

Another important aspect of university-community partnerships is a cross-sharing of resources. Access to youth, teachers, coaches, financial support, space, and, in some cases, transportation represent just some of the elements that community agencies and universities can provide to collaborative research or service programs. They also have the potential of providing less tangible resources. One of these is the way our partners can help generate research questions that help to link "craft knowledge" to social inquiry. This addresses the disconnect between real-world problems and research questions asked within the academic culture. In the end, we have found that serving underserved youth and at the same time carry out community-engaged inquiry have been highly tenable. 
The community connections also allow for program participants to experience the concept of service and learning in a significant way. For example, in both of our programs high school students provide values-based learning experiences to younger children. Connecting values-based content (i.e., personal and social responsibility) with this "real world" experience not only helps to enhance the students' leadership capacity but also bears the fruit of social capital through their work with children (Intrator \& Siegel, 2014).

\section{Key Features to Developing Partnerships}

Our university-community partnerships have been bound by various guidelines and considerations. These have served to support the creation of ideas and have helped to solidify the vitality of the partnerships. One of the most important features of our partnership is that both parties have a common program focus and interest. This includes basic philosophical assumptions about the youth who are in the program and the community from which they come (Barber, 1984). When we speak of communities, we refer to neighborhoods, community centers, and schools that are defined by their culture and/or mission. They include decision makers who make judgment on what is best for youth and how they will share with us in the collaborative process. From the academic side, we must also make decisions about the partners with whom we work. The kind of resources we can commit, the political and ideological ramifications for working with our community partners, and the research efforts that take place all effect the nature of our programs.

Another important feature of a successful partnership is having an agreement about the type of program and the desired outcomes of the joint endeavor. Whether it is keeping children off the streets, creating leadership qualities, improving academic performance, or enhancing social behavior in the classroom, the creation of outcomes must be jointly decided upon by both parties. Doing this creates a shared commitment to the program's mission and helps to identify ways in which the success of the program can be evaluated.

Equally important are the sharing of ideas and strategies to achieve the program's goals. We have found that having some similar ideas about the strategies for achieving our program goals need to be in place. Making a connection between resources and ideas enhances the feasibility for successful implementation. For us, ways of scheduling for program space, instructional time, transportation for children to the program site, and training and orientation of student participants all have taken place through collective efforts of both groups.

Finally, trust and respect between the program partners are also important. That is, each partner must be trusted to do the right thing. Knowing what the right thing is should be determined from the beginning of the program. Our partners have counted on us to deliver the program in a safe and credible way for children. On the other hand, we trust our partners to be able to provide transportation in a timely way, to provide instructional space when needed, and to communicate any changes in the school or center's schedule that affect the running of the program. This requires that communication lines be kept open between us and our partner. 
Knowing what goals cannot be compromised and where flexibility is possible insures that our work will be done in good faith. In the end, we all aspire to provide the wrap around support that is needed for young people to succeed in life. The individual role that each partner plays in our programs must then be guided by collective thought and wisdom - this will get us where we need to be.

\section{Out Partners and Their Contributions}

Our work at the university has allowed us to connect with various types of partners. Some of them are ones that we have reached out to and others have been those who looked to us to address particular needs. Some have been schools, others have been youth serving agencies, and others have been foundations, corporations, and philanthropists seeking opportunities to support sport-based programs. Although our partners are bounded by the goals of their own missions (e.g., Community in Schools, Health Access Project), they have, in some ways, created a useful link for us to broader community programs.

These partners have been vital resources by giving access to children and youth, funding and space to support program operations. The cross-over work of our high school students in providing instructional experience and, at the same time, offering meaningful after-school program support have enriched our leadership development efforts. In addition, research initiatives also have been supported through dollar gifts. Opportunity to do community-based inquiry has been made possible by our partners own need to show impact for what they do with children. While they have been asked to undertake evaluation of their own programs by partnering with us they have become a resource in sharing ways to examine program outcomes. Finally, the partners have showed us a spirit of commitment to have a positive impact on the youth they serve. This has affirmed the need to embrace a collective set of values that connects us together - values that insure that children will be heard, cared for, challenged, and competent.

\section{Two Examples of Sport-Based Youth Development Programs}

There are several sport-based programs that focus on developing personal qualities in children and youth. These programs operate in several different contexts with varying scopes and missions. For example, there are national programs like First Tee and Play it Smart (Petitpas, Cornelius, \& Raalte, 2008), where youth learn life skills through the game of golf and football. There are also smaller, more localized programs like Project Coach (Intrator \& Siegel, 2014) and Harlem RBI (Berlin, Dworkin, Eames, Mencini, \& Perkins, 2007), where leadership skills are fostered through many sport experiences. In all these programs, community partnerships become vital allies in helping youth transform their lives. Each has a distinctive approach to supporting and educating children. In providing a more comprehensive description of how the elements of community partnerships work, two of our sport-based programs are described: Urban Youth 
Squash Program and Project Effort Youth Leader Corps. Both programs rely on community partnerships to fortify program operations and are held on a university campus.

\section{Urban Youth Squash Program}

Urban Squash programs are guided by a set of standards developed by the National Urban Squash and Education Association (NUSEA; nationalurbansquash.org). Twenty-two programs have earned recognition by NUSEA as having sustainable budgets, adequate K-12 school partnerships, and evidence of promoting academic success among youth participants. Squash, a racquet sport played on an enclosed court, serves as the catalyst for engaging youth in programs that enhance their academic standing in school and likelihood of entering college. In 2015, the Charleston, South Carolina based urban squash program became the first NUSEA-recognized program in the South, buoyed by its partnership with the College of Charleston.

This partnership developed in part based on the convergence of interest between a new faculty member seeking pathways for community engaged scholarship and local philanthropists who had a vision for addressing educational inequities through the sport of squash. Early discussions led to the development of four areas of youth development goals that the Urban Squash program would pursue, including: (1) developing positive relationships among youth, families, and communities; (2) promoting personal and social responsibility; (3) developing physical literacy; and (4) promoting academic development. To achieve these goals, Chucktown Squash Scholars established a board of directors, employed two full-time staff members, managed community relationships, and provided reliable transportation to and from the university campus for youth participants. In return, the college provided faculty expertise to assist with program development and evaluation, access to athletic courts and classrooms, and developed opportunities for undergraduate students to mentor youth participants.

Chucktown Squash Scholars operates on the college campus nearly year-round, beginning in September and ending in May, followed by a multiweek summer program. Youth participants are transported from school to the college around 3:30 pm each Monday through Thursday where they participate in homework tutoring, academic mentoring, and squash practice. Before leaving the campus at 5:45 pm, the students are provided with a nutritious meal. Various efforts are made to leverage resources available on a college campus. For example, athletic teams volunteer as guest speakers, invite youth to games, and provide practice sessions. Art majors provide enrichment lessons to students followed by a tour of the campus art museum. Faculty members provide fitness assessments as part of a course focused on tests and measurements. The Honors College provides credit to students for their required community engagement hours. According to the founder of the program, this type of college exposure is the most valuable program outcome.

Youth participants attend community schools designated as Title 1 and recognized in the community as needing supplementary education and enrichment programs. Notably, parents of youth were engaged in the program and viewed as key partners. Some parents were challenged 
by extensive work and family obligations but their support was integral to the retention of most youth participants. At school, the program developed key advocates who worked as teachers or counselors. An advocate was someone who had knowledge of our sport-based youth

development model and believed it was effective. In the school, they could assist with getting information on school assignments, gaining cooperation from teachers and administrators, and recommending youth who might be a good fit for the program.

On the college campus, the kinesiology department facilitated the early development of the partnership simply by allowing a faculty member to coordinate the program and by providing access to classrooms and squash courts during dormant times. But, youth development programs who rely on private funding must expand their capacity to remain sustainable. As the program grew from 20 to 40 youth participants, the partnerships faced challenges. The program required physical office space to be eligible for some grant programs, youth participants were sometimes disruptive to other university activities, and senior administrators began to review potential liability issues that were overlooked with a small-scale program. Moreover, the college did not have squash courts that could support a larger program.

Questions of program capacity and resource allocations are complex and require the involvement of senior administrators. The urban squash program was successful in navigating these challenges through the strategic thinking of its board of directors. The board consisted of community leaders, business leaders, and education advocates who oversaw program staff, led fundraising efforts, and ultimately negotiated a groundbreaking partnership agreement with the college. As most universities do, the college was seeking to build relationship in the community to enhance its own strategic initiatives including facilities development and scholarships. The urban squash community provided a space where the college had not previously developed relationships. Over the course of one year, the board developed a proposal to build a squash center on the college campus that met international standards. The board would lead the fundraising effort in collaboration with college administration. In return, the college would provide access to their resources for the foreseeable future. Moreover, the college would be one of only a few places in the south with state-of-the-art squash courts that may host special events and enhance applications for admissions among students with an interest in squash. Following an extensive negotiation process, a memorandum of understanding was signed that allows the squash program to grow to serve over 100 youth participants and the college to construct five state-of-the-art squash courts on its campus.

This partnership between an urban squash program and a university began with small and attainable goals. These initial goals provided a foundation for the program and a record of small, but meaningful, success stories through which the program advocated for more resources. Most importantly, perhaps, the urban squash program could make contributions to the university mission related to community engagement and resource development. The service to local Title 1 schools addressed a critical need in Charleston and the novel use of the sport of squash to promote youth development helped establish a unique collection of constituents for the university to build relationships with. The urban squash program, in turn, addressed logistical 
issues related to sustaining a youth development program and adopts most of the responsibilities that may inhibit youth development programs (e.g., fundraising, transportation) sustainability on a university campus.

As the partnerships enters a new phase, there may be new challenges. Increased enrollments of youth participants require coordination between multiple schools and multiple families. The youth also bring varying skills and interests in squash. The urban squash program is constantly challenged with hiring staff with technical expertise in squash and pedagogy along with a commitment to teaching positive youth development through sports. These challenges are addressed, in part, through the network of NUSEA programs and their alumni. Charleston-based urban squash staff are increasingly consulting with leaders of similar programs to generate a set of best practices that can sustain their program into the future.

\section{Project Effort Youth Leaders Corps}

The Charleston program portrays a unique partnership developed around a unique sport venue. Clearly, its intent was to excite youth to engage in an experience that enriched both mind and body. Another such partnership between the University of North Carolina at Greensboro (UNCG) and its public schools, called Project Effort Youth Leader Corps, was also formed to address a community need related to school failure of its students. Over its 24-year history, the Project Effort Youth Leader program has provided values-based experiences for underserved children in the Greensboro community. The genesis of the program, called Project Effort, started with a partnership between the university and a local elementary school. Several students were struggling academically and socially in their classrooms. Their school biographies indicated they had high rates of suspension, multiple office referrals, and lousy grades. The principal thought that their participation in an after-school sport program, on a university campus, would increase the chances of doing better in school. Transportation to and from the university site were provided by the school. Don Hellison's Teaching Personal and Social Responsibility (TPSR) Model — respecting each other, trying one's best, setting personal goals, and helping and leading each other (Hellison, 2011) _ guided the delivery of the learning experiences. A mentoring component was also added to the program where university students met with the students during the week. The mentors encouraged the students to apply the values learned in the sport program to their classroom work.

As the Project Effort children progressed through their elementary school grades, a middle school program was added. Eventually, those children who stayed with the Project Effort program throughout their elementary and middle school years were given the opportunity to lead their own program as high school students. This program was called the Youth Leader Corps (YLC). Younger underserved children from various community centers and schools were provided values-based learning experiences from the high school leaders. In addition, the leaders extended their service work to the other segments of the community. One of these was a nonprofit organization (i.e., Guilford Interfaith Hospitality Network) that provided temporary 
living places for homeless families. This program included various churches that would give shelter to families who were temporarily looking for housing, The YLC leaders became part of this network where they would provide food and bedding on the university campus for several homeless family members.

Forming partnerships with community members was well received by the university. During that period, the university was seeking to establish itself as a community engaged institution. Community foundations also became important partners as they provided the financial assistance and advocacy needed to support various aspects of the program. Having past connections with community members, a common interest in helping children, and an opportunity to share resources all helped to further solidify the bond between the university and its partners. Similar to the Chucktown Squash Scholars program, transportation for program participants to and from the university site were provided by the community partners. In addition, the UNCG undergraduates were able to gain service learning hours by volunteering in the program.

Project Effort has changed over the past several years. The delivery of the Project Effort Program is now delivered by selected high school students from an alternative high school, called a middle college, located on the UNCG campus. Six years ago, a middle college was placed on the campus as a result of several years of collaborative efforts by the second author and the public schools to provide an alternative educational experience for at-risk high school children. The motivation for creating this school came from seeing many children who were working in Project Effort's YLC hitting the proverbial "brick wall" during their high school experience. They were either skipping school or not going to classes. So, starting an alternative school seem to be a possible way of providing an educational bridge for the youth leaders and other at-risk students. One unique feature of a middle college high school is that it is located on a university or college campus. Its basic mission is to provide a public education for "disaffected" students. Small class instruction allows students to explore career possibilities. In addition, enrollment in university classes is offered for students who are academically ready.

In keeping with the school's mission, the YLC program was put in place. Its primary purpose was to have selected students to provide an after-school sport program for other underserved children and youth in the community. That is, they would provide the "Project Effort" experience for others. Most of the leaders were selected based on their past academic record, behavioral issues in school, and/or strong interest in becoming a "youth leader." Two groups of youth leaders created lessons that incorporated both sport skills and the TPSR responsibility goals. They taught them to other elementary age children from various segments of the Greensboro community, such as the Boys and Girls Clubs, municipal recreation centers, refugee community centers, extended school programs. Compassion for others was (and continues to be) the cornerstone of the YLC program. Today, the YLC runs twice each week during the school year, with each group of leaders teaching on separate days of the week. On one of the days, the leaders travel to a Title 1 elementary school where they work with 30 fourth and 
fifth grade students. The students have been selected by their school counselor and teachers to participate in the Project Effort after-school program. Their struggles in their classroom work have made them vulnerable to school failure. The second program is held later in the week at the university. The second group of leaders work with children from three underserved communities, each populated with refugee families from Mexico, Africa, and Indonesia. Thirty-five children (age 8-12 years old) are transported to the campus by university vans. Continual contact with community leaders enabled program leadership to adapt to time and space changes and plan for any additions to the program agenda. In addition, school administrators and staff (i.e., principal, liaison, and counselor) have become important informants for how the high school leaders are doing in their school work.

\section{Conclusion}

We believe that the Project Effort Youth Leader Corps and Chucktown Squash Scholars programs equip youth for their high-stakes journey of development. The outcomes that we seek go beyond just being responsible for planning and teaching children. Making good decisions, being an excellent communicator and savvy reader of social cues, and acquiring a sense of community connectedness are some the outcomes we hope our leaders gain from their program experiences. During their lifetime both programs have worked to create a culture of possibilities based on the potential of youth participants to succeed in the programs and beyond. We have been fortunate to have like-minded partners who share a similar vision of pushing children to reach their full potential.

Kinesiology departments have a role to play in promoting positive youth development through sports and physical activity. We have learned through our experience, and other examples presented in the literature (e.g., Walsh, 2013), that planning for the basic "nuts and bolts" of programs remains a constant challenge. These issues include things like transportation, recruitment, and memorandums of understanding. Solving these basic challenges only provides a foundation for a successful community engagement partnership. In the examples presented here, we have partnered with community organizations who had the capacity to solve some of the basic problems while we leveraged the unique offerings of a university and kinesiology department. For example, our community partners were often more equipped to solve transportation logistics while our kinesiology departments could provide facilities, volunteers, and assessment.

Another common thread in our two programs has been an eye toward sustainability. In other words, we aimed to make our programs available to youth over an extended period. Project

Effort has succeeded for over 24 years and the long-term success of Chucktown Squash Scholars is still to be determined. In both cases, university faculty members served as champions of the program on campus and successfully made connections between the positive youth development and the strategic priorities of the university. Others who aim to create similar partnerships 
are encouraged to consider how their programs are mutually beneficial to the university and to the community. For example, our colleagues at universities focused primarily on how teaching undergraduate students might make linkages between positive youth development programs and undergraduate student learning outcomes. As the recent meeting of the American Kinesiology Association has shown, community engagement partnerships are thriving in kinesiology departments. Sharing our successes and challenges through forums such as this may continue to enhance our efforts and make a difference in the lives of youth.

\section{References}

Barber, B. (1984). Strong democracy: Participatory politics for a new age. Berkeley, CA: University of California.

Berlin, R.A., Dworkin, A., Eames, N., Mencini, A., \& Perkins, D.F. (2007). Examples of sport-based youth development programs. New Directions for Student Leadership, 115, 85-106.

Driscoll, A. (2008). Carnegie community-engaged classification: Intentions and insights. The Magazine of Higher Learning, 40, 38-41. doi:10.3200/CHNG.40.1.38-41

Hellison, D. (2011). Teaching responsibility through physical activity. Champaign, IL: Human Kinetics.

Hemphill, M.A., \& Richards, K.A.R. (2016). "Without the academic part, it wouldn't be squash": Youth development in an urban squash program. Journal of Teaching in Physical Education, 35, 263-276. doi:10.1123/jtpe.2015-0109

Hemphill, M.A., Richards, K.A., Blankenship, B.T., Beck, S., \& Keith, D. (2012). Making PALS through partnerships: A collaboration to promote physically active Lafayette students. Journal of Physical Education, Recreation \& Dance, 83, 23-36. doi:10.1080/07303084.2012.10598843

Holt, N.L. (2016). Positive youth development through sports. New York: Routledge.

Intrator, S., \& Siegel, D. (2014). The quest for mastery: Positive youth development through out-of-school programs. Cambridge, MA: Harvard Education Press.

Lee, O., \& Martinek, T. (2013). Navigating two cultures: An investigation of cultures of responsibility-based physical activity program and school. Research Quarterly for Exercise and Sport, 80, 230-240. doi:10.1080/02701367.2009.10599557

Martinek, T. (2016). Project Effort: Creating responsible leadership through values-based learning. Active and Health Magazine, 23, 43-46.

Petitpas, A.A., Cornelius, A., \& Van Raalte, J. (2008). It's all about relationships. In N.L. Holt (Ed.), Positive Youth Development through Sport (pp. 61-70). London: Routledge.

Putnam, R. (2001). Bowling alone: The collapse and revival of American community. New York, NY: Simon \& Schuster.

Strand, K., Marullo, S., Cutforth, N., Stoecker, R., \& Donahue, P. (2003). Community-based research: Principles and practices for higher education. San Francisco, CA: Jossey-Bass. 
Walsh, D. (2013). Best practices in university-community partnerships: Lessons learned from a physical activity-based program. Journal of Physical Education, Recreation \& Dance, 77, 45-56. doi:10.1080/07303084.2006.10597863 